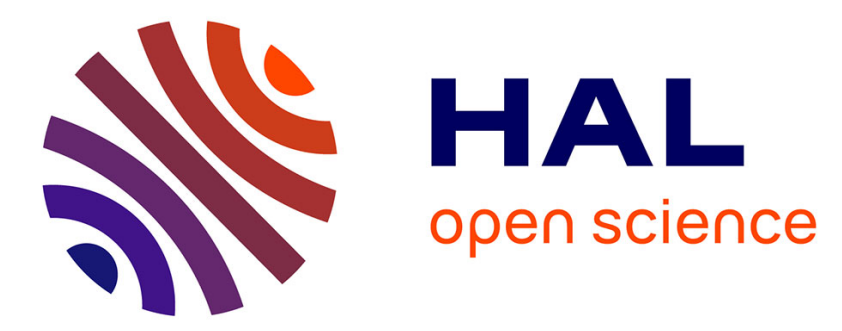

\title{
Plant growth dynamics and root morphology of little-known species of Chenopodium from contrasted Andean habitats
}

Ricardo Alvarez-Flores, Thierry Winkel, David Degueldre, Carmen Del Castillo, Richard Joffre

\section{To cite this version:}

Ricardo Alvarez-Flores, Thierry Winkel, David Degueldre, Carmen Del Castillo, Richard Joffre. Plant growth dynamics and root morphology of little-known species of Chenopodium from contrasted Andean habitats. Botany / Botanique, 2014, 92 (2), pp.101-108. 10.1139/cjb-2013-0224 . ird-02381077

\section{HAL Id: ird-02381077 \\ https://hal.ird.fr/ird-02381077}

Submitted on 27 Nov 2019

HAL is a multi-disciplinary open access archive for the deposit and dissemination of scientific research documents, whether they are published or not. The documents may come from teaching and research institutions in France or abroad, or from public or private research centers.
L'archive ouverte pluridisciplinaire HAL, est destinée au dépôt et à la diffusion de documents scientifiques de niveau recherche, publiés ou non, émanant des établissements d'enseignement et de recherche français ou étrangers, des laboratoires publics ou privés. 


\title{
Plant growth dynamics and root morphology of little-known species of Chenopodium from contrasted Andean habitats
}

\author{
Ricardo Alvarez-Flores, Thierry Winkel, David Degueldre, Carmen Del Castillo, and Richard Joffre
}

\begin{abstract}
Plant morphology determines the access to soil resources, a feature crucial for early growth in annual species. Plant growth and root traits in little-known species of Andean chenopods were compared with the hypothesis that plants from low-resource habitats show traits that enhance resource capture. Three cultivated Chenopodium populations (two populations of the tetraploid Chenopodium quinoa Willd., one population of the diploid Chenopodium pallidicaule Aellen) and one population of their wild tetraploid relative Chenopodium hircinum Schrad. were grown in pots under nonlimiting conditions over nine weeks of early vegetative growth. All populations followed the same sequence of biomass allocation and showed similar maximal values of shoot and root relative growth rates (RGR). Population differences in plant biomass, net assimilation rate, total root length, and specific root length were associated with seed mass ranking and species ploidy level. Chenopodium quinoa produced less branched stems and maintained high root RGR for a longer time than the other two species, and the $C$. quinoa population from low-resource habitat showed a faster main root growth. These results show that $C$. pallidicaule developed a plant growth syndrome adapted to cold, high-altitude habitats, while $C$. quinoa from low-resource habitats showed an improved capacity to explore soil at depth in early growth stages.
\end{abstract}

Key words: biomass allocation, phenotypic variation, plant growth analysis, root growth, root morphology, wild and cultivated species.

Résumé : La morphologie des plantes détermine l'accès aux ressources du sol, un élément crucial pour la croissance juvénile des plantes annuelles. La croissance des plantes et les traits racinaires de chénopodes peu connus des Andes ont été comparés avec l'hypothèse que les plantes d'habitats pauvres en ressources présentent des traits qui améliorent la capture des ressources. Trois Chenopodium cultivés (deux populations tétraploïdes de Chenopodium quinoa Willd., une population diploïde de Chenopodium pallidicaule Aellen) et une population de leur parent sauvage tétraploïde Chenopodium hircinum Schrad. ont été cultivés en pots en conditions non limitantes durant neuf semaines de croissance végétative. Toutes ces populations montrent la même séquence d'allocation de la biomasse et des valeurs similaires des taux de croissance relative (RGR) des tiges et des racines. Les différences inter-populations de production de biomasse, taux d'assimilation nette, longueur racinaire totale, et longueur spécifique des racines sont associées à la masse des graines et au niveau de ploïdie des espèces. Chenopodium quinoa produit des tiges moins ramifiées et maintient des RGR de racines plus élevés durant plus longtemps que les deux autres espèces, et la population de C. quinoa issue de l'habitat pauvre en ressources présente une croissance plus rapide de la racine principale. Ces résultats montrent que $C$. pallidicaule développe un syndrome de croissance adapté aux habitats froids de haute altitude, tandis que C. quinoa de l'habitat pauvre en ressources montre une meilleure capacité d'exploration du sol en profondeur pendant la phase de croissance juvénile.

Mots-clés : allocation de biomasse, variation phénotypique, analyse de croissance des plantes, croissance racinaire, morphologie racinaire, espèces sauvages et cultivées.

\section{Introduction}

The morphology of individual plants largely controls the balance between resource capture and resource use during the plant's life cycle (Garnier 1991; Reich et al. 1998). Both natural and human selection have produced a range of plant forms and organ allometry that result in plant growth, biomass allocation, and morphological traits varying systematically among species originating from contrasted habitats (Reich et al. 1998; Ross-Ibarra et al. 2007). In low-resource habitats, plant survival and growth depend directly on these morphological root traits that allow the plants to capture limited or ephemeral resources from the soil ( $\mathrm{Yu}$ et al. 2007). These traits influence the productivity of both natural and agricultural ecosystems (Wolfe et al. 2008), and in many crop species, selection for grain production has deliberately modified the aerial plant parts but also, in an unconscious way, the root system (Siddique et al. 1990; Palta et al. 2011).

In the Andes, under contrasted and often extreme habitats, a diversity of Chenopodium species has flourished, some as spontaneous chenopods (e.g., Chenopodium hircinum Schrad., Chenopodium petiolare Kunth, Chenopodium carnosolum Moq.), others as cultivated species such as quinoa (Chenopodium quinoa Willd.) and cañahua ${ }^{1}$ Fn1 (Chenopodium pallidicaule Aellen) (Wilson 1990; Bonifacio 2003).

Received 5 September 2013. Accepted 28 November 2013.

R. Alvarez-Flores, D. Degueldre, and R. Joffre. Centre National de la Recherche Scientifique, Centre d’Écologie Fonctionnelle et Évolutive, UMR 5175, Campus du CNRS, 1919 Route de Mende, F-34293 Montpellier Cedex 05, France.

T. Winkel. Institut de Recherche pour le Développement, Centre d’Écologie Fonctionnelle et Évolutive, UMR 5175, Campus du CNRS, 1919 Route de Mende, F-34293 Montpellier Cedex 05, France.

C. Del Castillo. Universidad Mayor de San Andrés, Facultad de Agronomía, La Paz, Bolivia.

Corresponding author: Thierry Winkel (e-mail: thierry.winkel@ird.fr).

${ }^{1}$ Also written as cañihua, kañihua, cañigua, cañiwa, etc. 
Table 1. Geographic origin and mean $( \pm \mathrm{SE})$ seed mass $(n=120)$ of the four studied Chenopodium populations.

\begin{tabular}{llllllccc}
\hline Species & Code & Provenance & Latitude & Longitude & Altitude $(\mathrm{m})$ & $\begin{array}{l}\text { Rainfall } \\
\left(\mathrm{mm} \cdot \mathrm{year}^{-1}\right)\end{array}$ & SOM range $(\%)^{a}$ & $\begin{array}{l}\text { Seed mass } \\
\left(\mathrm{mg}^{\prime} \cdot \mathrm{seed}^{-1}\right)\end{array}$ \\
\hline C. quinoa & QC & Cunco, Chile & $38^{\circ} 56^{\prime} \mathrm{S}$ & $72^{\circ} 03^{\prime} \mathrm{W}$ & 200 & 1200 & $7-29$ & $2.09 \pm 0.04$ \\
C. quinoa & QB & Jirira, Bolivia & $19^{\circ} 51^{\prime} \mathrm{S}$ & $67^{\circ} 34^{\prime} \mathrm{W}$ & 3700 & 250 & $0.2-0.4$ & $4.89 \pm 0.10$ \\
C. hircinum & HI & Aranjuez, Bolivia & $16^{\circ} 33^{\prime} \mathrm{S}$ & $68^{\circ} 36^{\prime} \mathrm{W}$ & 3200 & 550 & $0.4-1.5$ & $1.50 \pm 0.04$ \\
C. pallidicaule & PA & La Paz, Bolivia & $17^{\circ} 30^{\prime} \mathrm{S}$ & $68^{\circ} 36^{\prime} \mathrm{W}$ & 3600 & 550 & $0.4-1.5$ & $0.60 \pm 0.01$ \\
\hline
\end{tabular}

Note: SOM, soil organic matter; SE, standard error.

a Sources: QC, Alvear et al. (2005) and Reyes et al. (2011); QB, HI, and PA, Lebonvallet (2008).

Chenopodium hircinum grows today in lowlands, as well as highlands, of Bolivia and Argentina and might be the wild progenitor of cultivated quinoa, both being allotetraploid relatives (Mujica et al. 2001; Bonifacio 2003; Pearsall 2008). Quinoa is supposed to have been domesticated in the semiarid and cold highlands of Peru and Bolivia. This grain crop shows an ample niche diversification from cold highland deserts down to tropical intermontane valleys and temperate ocean littoral, resulting in dozens_ of local varieties and landraces (Bonifacio 2003) with a promising potential outside its original area of distribution (Bertero et al. 2004). Cañahua may have originated as a grain and forage crop in dry areas of extreme elevation and shallow soils (Gade 1970; Bonifacio 2003; Bruno 2006; Pearsall 2008). According to Wilson (1990) and Mujica et al. (2001), the diploid genome of cañahua could have combined with that of $C$. petiolare or $C$. carnosolum to produce the allotetraploid $C$. hircinum.

Comparative studies of plant morphology and growth dynamics can bring some insights regarding different plant traits developed under natural and human selection among these Andean chenopods. In quinoa, genetic differentiation corresponding to broadscale ecogeographic patterns has been inferred from molecular markers (Del Castillo et al. 2007; Costa Tártara et al. 2012), morphological traits (Rojas 2003; Bertero et al. 2004; Bhargava et al. 2007), or both (Anabalón Rodríguez and Thomet Isla 2009). However, this information is still lacking for its relatives, and in all cases, the root traits of these Andean chenopods remain largely unknown despite their crucial role for the capture of soil water and nutrient resources. Particularly in harsh and variable environments, in which fast and early rooting is vital to capture ephemeral soil nutrients and deep water, root traits such as total root length, maximum rooting depth, and root diameter are critical for the successful establishment of the plants (Materechera et al. 1992; Lamb et al. 2012).

The present study addresses the differences in plant morphology and growth patterns of one wild and two cultivated Andean chenopod species with the hypothesis that plants from lowresource habitats have developed traits that enhance soil resource capture. To test for this, a comparative study was conducted to investigate plant growth and rooting patterns during the vegetative growing phase to identify contrasting plant traits and their ecological significance in contrasted habitats.

\section{Material and methods}

\section{Studied species and experimental design}

The study was conducted in a glasshouse at the CEFE (Centre d'Écologie Fonctionnelle et Évolutive, Montpellier, France; $43^{\circ} 38^{\prime} 19^{\prime \prime} \mathrm{N}$, $\left.3^{\circ} 51^{\prime} 46^{\prime \prime} \mathrm{E}\right)$ under uniform, nonlimiting growth conditions. Considering a population as a group of interbreeding individuals from the same area, four Chenopodium populations from contrasted habitats were compared: cultivated $C$. quinoa from temperate, rainy lowlands in Chile (high-resource habitat), cultivated C. quinoa from arid and cold highlands in southern Bolivia (lowresource habitat), and cultivated $C$. pallidicaule (cañahua) and wild C. hircinum, both from semiarid and cold highlands in northern Bolivia (Table 1). Planning weekly harvests from 7 days after sowing (DAS) until 63 DAS with seven replicates in each population, seeds were sown in 252 free-draining pots containing $7 \mathrm{~L}$ of a sandy substrate (extra silica, 99\%; $\mathrm{pH} 7.5$ ) and watered with 1.2 L-pot ${ }^{-1}$ of a nutrient solution (N, $16 \%$;, $10 \%$;, $24 \%$; $\mathrm{MgO}, 3 \%$; micronutrients, $2.5 \mathrm{~g} \cdot \mathrm{L}^{-1}$ ). Over the course of the experiment, the same nutrient solution was applied to maintain the substrate water content near $90 \%$ of the field capacity. Air temperature (range, $10-29{ }^{\circ} \mathrm{C}$; mean, $25.1 \pm 0.6{ }^{\circ} \mathrm{C}$ ), soil temperature (range, $15-29^{\circ} \mathrm{C}$ ), air relative humidity (range, $55 \%-75 \%$ ), and light intensity at midday (range, $870-4115 \mu \mathrm{mol} \cdot \mathrm{m}^{-2} \cdot \mathrm{s}^{-1}$; mean, $2890 \pm$ $142 \mu \mathrm{mol} \cdot \mathrm{m}^{-2} \cdot \mathrm{s}^{-1}$ ) were recorded at half-hour intervals. After seedling emergence, pots were thinned to 1 plant pot $^{-1}$ and placed in a randomized design with a density of 16 plants $\cdot \mathrm{m}^{-2}$.

\section{Plant sampling and measurements}

At each harvest date, individual plants were divided into roots, main stem, secondary stems, leaves, and, when present, floral buds. Leaves were scanned at $600 \mathrm{dpi}$ and the total leaf area per plant $\left(\mathrm{LA}, \mathrm{cm}^{2}\right.$ ) was determined with the SigmaScan Pro 5 software (Systat Software Inc., Chicago, Illinois, USA). Shoot samples were then oven-dried at $70{ }^{\circ} \mathrm{C}$ for $48 \mathrm{~h}$ and weighed. Roots were gently washed of sand and stained with methylene blue $\left(4 \mathrm{~g} \cdot \mathrm{L}^{-1}\right)$ to increase contrast before scanning. The entire root system of each plant was digitized to 28 DAS. From that harvest on, a representative subsample of the root system was selected on a mass basis. Roots were prepared according to Roumet et al. (2006) before scanning at a resolution of $400 \mathrm{dpi}$ and analyzing with WinRhizo Pro 2003a software (Regent Instruments Inc., Sainte-Foy, Quebec, Canada) to measure main root length (MRL, $\mathrm{m}$ ), lateral root length (LRL, m), total root length (TRL, m), average main root diameter (MRD, mm), average lateral root diameter (LRD, $\mathrm{mm}$ ), and total root projected area $\left(\mathrm{RA}, \mathrm{cm}^{2}\right)$. Finally, roots were dried at $70^{\circ} \mathrm{C}$ for $48 \mathrm{~h}$ and weighed.

\section{Plant morphology and growth parameters}

From the various mass and length measurements, the following values were calculated: mass fractions of the leaves, stems, and roots (LMF, SMF, RMF, respectively, \%) relative to the total plant dry mass (TPM, g), root to shoot mass ratio $\left(R / S, g \cdot g^{-1}\right)$, leaf area to whole-plant mass ratio (LAR, $\mathrm{m}^{2} \cdot \mathrm{kg}^{-1}$ ), root area to leaf area ratio (RA/LA, $\mathrm{cm}^{2} \cdot \mathrm{cm}^{-2}$ ), specific leaf area (SLA, $\mathrm{m}^{2} \cdot \mathrm{kg}^{-1}$ ), and specific

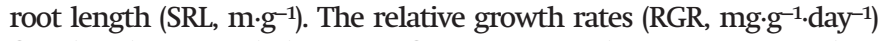
for the shoots and the roots for successive harvests were calculated following Hoffmann and Poorter (2002). The net assimilation rate (NAR, $\mathrm{g} \cdot \mathrm{m}^{-2} \cdot \mathrm{day}^{-1}$ ) was determined using the equation of Vernon and Allison (1963).

\section{Data analyses}

Statistical procedures were applied using Statistica version 7.1 software (StatSoft ferences in plant traits among populations were tested using factorial analysis of variance (ANOVA) after log transformation of the data when necessary. Tukey's honestly significant difference (HSD) test was used to compare population means. The means and standard errors of shoot and root RGR were calculated using the method of Causton (1991). Following Coleman et al. (1994), plant growth data were plotted as a function of the logarithm of the whole-plant biomass to avoid size effects when comparing populations. To account for these size effects, analyses of covariance were performed to compare plants growth traits among popula- 
tions, with shoot RGR, root RGR, and NAR as the dependent variables, plant biomass as a covariate, and testing for a possible interaction between the covariate and the factor "populations".

\section{Results}

Plant growth, biomass allocation, and leaf traits

Average seed mass differed 8.1-fold among the four populations, with quinoa of low-resource habitat and cañahua showing the highest and the lowest values, respectively (Table 1). At all harvests, cañahua had the smallest plants, whereas the other three populations showed comparatively small differences among them (Fig. 1). At 63 DAS, plants of cañahua were about one-tenth the size of the other populations $\left(\mathrm{LA}=0.029 \mathrm{~m}^{2} \cdot\right.$ plant $^{-1}$ and $\mathrm{TPM}=1.6 \mathrm{~g} \cdot \mathrm{plant}^{-1}$ compared with averages of $0.28 \mathrm{~m}^{2}$. plant ${ }^{-1}$ and $22.2 \mathrm{~g}$.plant ${ }^{-1}$, respectively, in the other three populations).

The general patterns of leaf, root, and whole-plant growth were similar in the four populations, with a slow growth until 35 DAS, followed thereafter by an accelerated biomass production and leaf area expansion (Figs. 1a, 1b). Main root elongation showed an accelerated growth period limited to 42 DAS, followed by a halting incañahua and a slow growth in the other three populations (Fig. 1c). In general, the quinoa from low-resource habitat showed a faster root growth than in the other populations, with MRL reaching $1 \mathrm{~m}$ between 42 and 49 DAS, one to two weeks earlier than in quinoa from high-resource habitat and in C. hircinum. At each harvest, MRL in cañahua remained less than half that of the other three populations.

Initially, the biomass allocation to leaves, stems, and roots was similar in the four populations, with a dominant part $(\geq 50 \%)$ allocated to leaves (Supplementary Fig. S12). At 14 DAS, the leaf mass fraction (LMF) was maximum in all populations, reaching values near 70\%. It decreased from then on, to the benefit of the roots for the next two or three weeks and later to the benefit of the stems up to 56 DAS. The stem mass fraction (SMF) reached about $40 \%$ by the end of the growing period, without noticeable difference among populations. However, in both quinoa populations, the proportion of secondary stems remained negligible, whereas it accounted for up to one-third of the total stem biomass in C. hircinum, and two-thirds of it in cañahua. Under nonlimiting conditions, the root mass fraction (RMF) never exceeded $25 \%$ of the total plant mass in the four populations. Floral bud development remained negligible in all populations.

The root to shoot mass ratio $(R / S)$ was highly variable in the first two weeks when plant size was very small, and the ratio between minute biomass quantities resulted in erratic $R / S$ values (Supplementary Fig. S2a). $R / S$ reached maximum values at 28 DAS (35 DAS in cañahua) and declined thereafter. The increase at 28 DAS was much more pronounced in the quinoas than in the other two populations $(R / S \approx 0.25$ on average in these populations compared with 0.4 in the quinoas) and resulted in constantly higher $R / S$ values in the quinoa populations until the end of the growing period. The root area (RA) was one to two times larger than the leaf area (LA) in the first week (Supplementary Fig. S2b). After 7 DAS, LA expanded rapidly and RA/LA declined to nearly 0.5 , with values remaining fairly constant until 49 DAS without difference among populations. In the last two weeks of the experiment, the beginning of leaf senescence led to higher, but also more variable, RA/LA values.

The specific leaf area (SLA) ranged between $30 \mathrm{~m}^{2} \cdot \mathrm{kg}^{-1}$ and $65 \mathrm{~m}^{2} \cdot \mathrm{kg}^{-1}$ over the whole period (Supplementary Fig. S3a). Showing relatively high values in the smallest plants, SLA maintained values near $45 \mathrm{~m}^{2} \cdot \mathrm{kg}^{-1}$ at medium plant sizes (ln-transformed TPM (ln TPM) between 5 and 9) before dropping again in the largest plants. After an initial increase over the first two harvests, the leaf
Fig. 1. Time variation in plant biomass $(a)$, leaf area $(b)$, and main root length $(c)$ in $C$. quinoa from low-resource habitat $(\triangle)$, C. quinoa from high-resource habitat $(\mathbf{\Delta}), C$. hircinum $(\mathbf{O})$, and C. pallidicaule $(\bigcirc)($ mean \pm SE, $n=7$, vertical bars show SE unless eclipsed by the symbol).

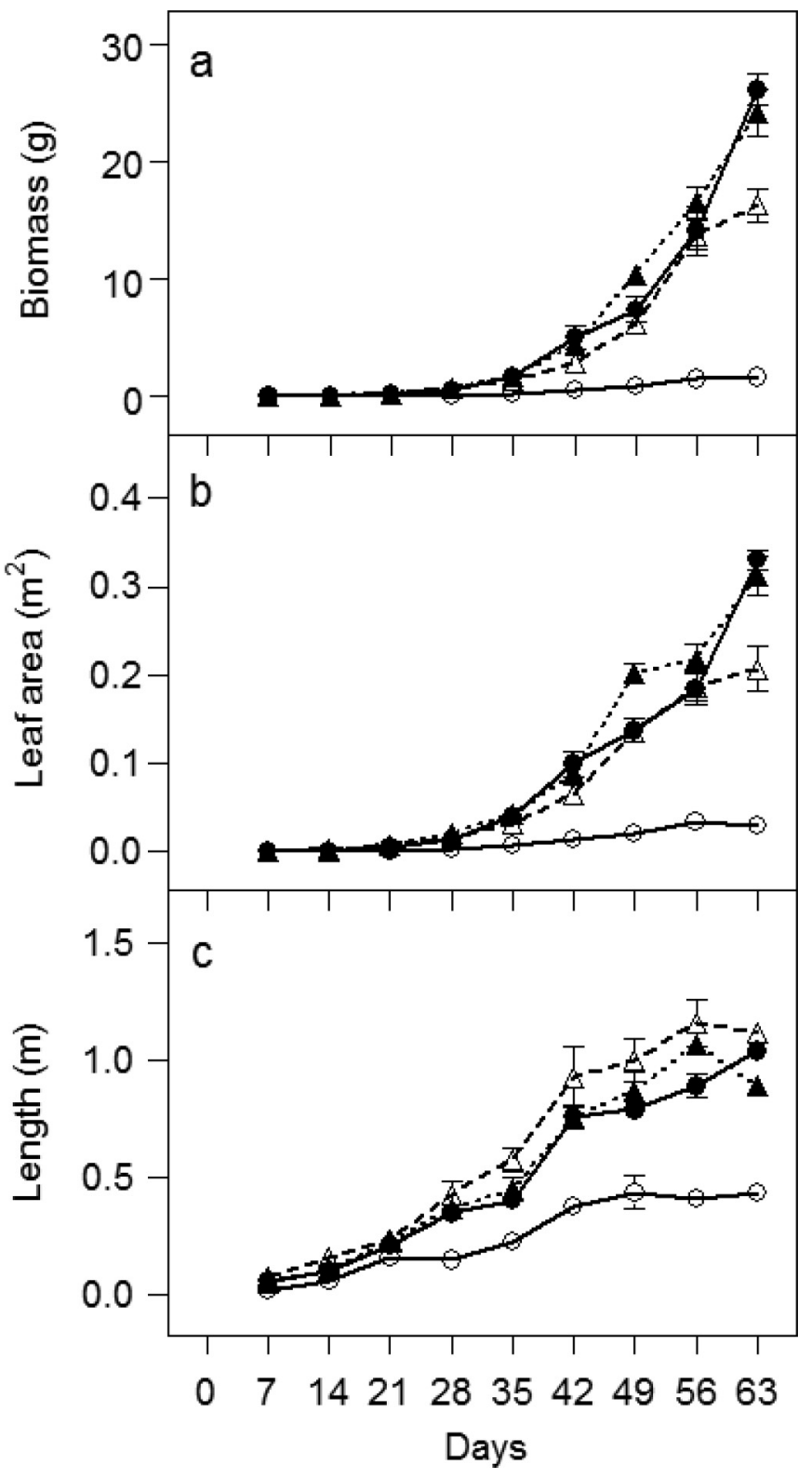

area ratio (LAR) declined continuously as plant size increased and did not differ among populations (Supplementary Fig. S3b). Considering the four populations and the entire vegetative growth period, SLA and LAR showed a high positive correlation $(r=0.72$, $n=36, P<0.001)$.

\section{RGR and net assimilation rate}

In the four populations, RGR showed similar patterns of variation in relation to the total plant biomass (Fig. 2), with a highly F2 significant correlation between root and shoot RGR ( $r=0.89, n=$ $32, P<0.001$, for all populations). In all cases, shoot and root RGR had similar high values around $300 \mathrm{mg} \cdot \mathrm{g}^{-1} \cdot$ day $^{-1}$ at small plant sizes and stabilized near $150 \mathrm{mg} \cdot \mathrm{g}^{-1} \cdot \mathrm{day}^{-1}$ at medium plant sizes (shaded area in Fig. 2), before decreasing again by the end of the

${ }^{2}$ Supplementary data are available with the article through the journal Web site at http://nrcresearchpress.com/doi/suppl/10.1139/cjb-2013-0224. 
Fig. 2. Relationship of shoot relative growth (RGR) (dashed lines) and root RGR (solid lines) to the total plant mass (ln-transformed) in C. quinoa from low-resource habitat (QB), C. quinoa from high-resource habitat $(\mathrm{QC})$, C. hircinum (HI), and C. pallidicaule (PA) (mean \pm SE, $n=7$, vertical bars show SE unless eclipsed by the symbol. Data points in the shaded area are statistically different from those in the neighbouring areas).

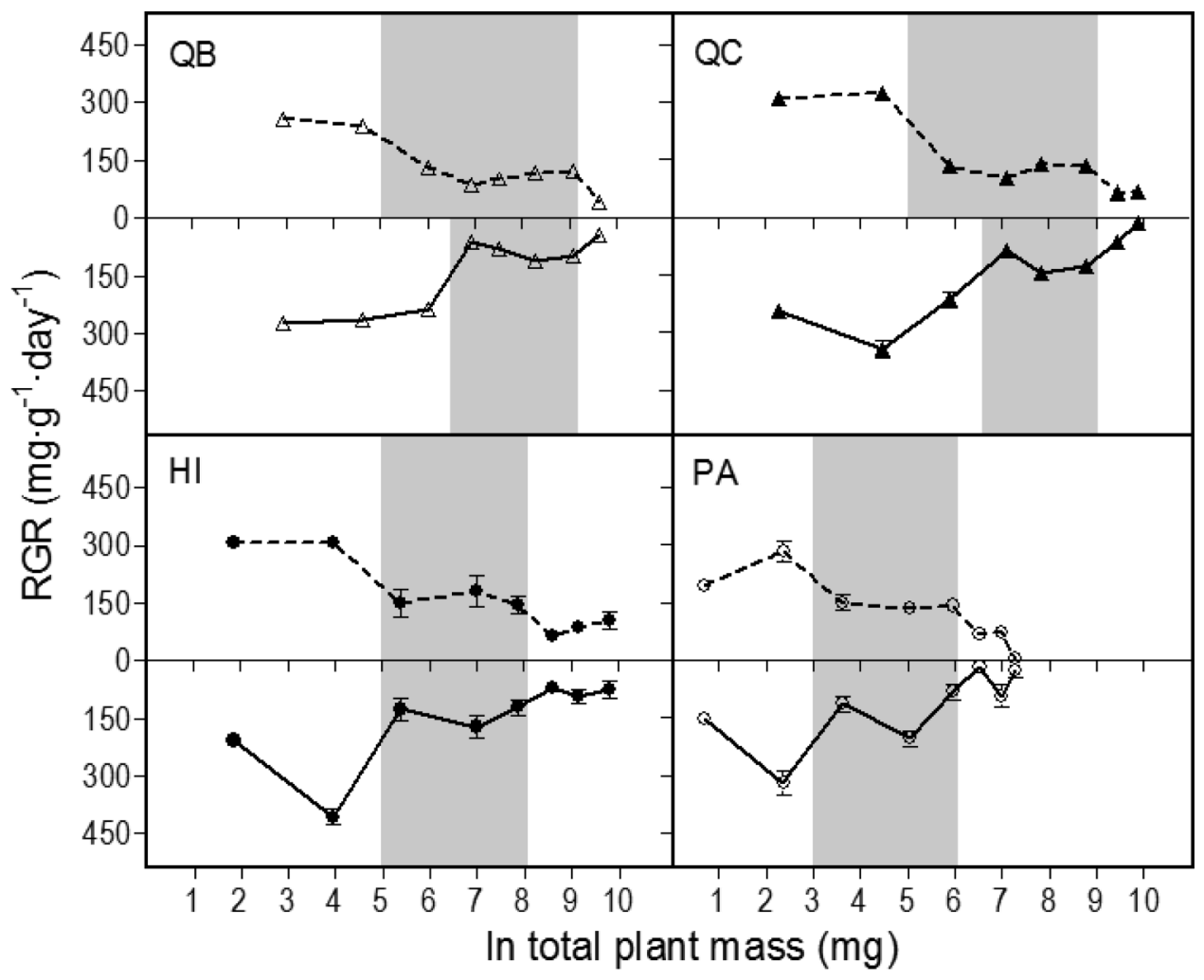

growing period. The gradual decline in both shoot and root RGR was associated with decreases in SLA and LAR at similar plant sizes (Supplementary Fig. S3). Interestingly, in the two quinoa populations, the decline in shoot RGR did not parallel that of root RGR because shoot RGR dropped at $\ln$ TPM $>5$ (TPM $>0.15 \mathrm{~g}$ ) while root RGR remained at or near their high initial values up to $\ln \mathrm{TPM}=6$ (TPM $=0.40 \mathrm{~g})$. The transition from high to intermediate shoot RGR at $\ln$ TPM $\approx 5$ was similar for $C$. hircinum and the two quinoa populations, whereas in cañahua, shoot (and root) RGR dropped for $\ln$ TPM as low as 3 (TPM $=0.02 \mathrm{~g}$ ). Thus, the studied populations differed less in their absolute values of shoot or root RGR than in the dynamics of RGR in relation to plant size, with cañahua showing RGR reductions at smaller plant sizes than in the other three populations and cultivated quinoas maintaining high root RGR in plants of medium sizes when this trait was already reduced by half in $C$. hircinum and cañahua.

NAR varied between 1.7 and $12 \mathrm{~g} \cdot \mathrm{m}^{-2}$. day $^{-1}$ for all populations, with declining values as plant biomass increased (Fig. 3). Cañahua showed significantly lower NAR $(P<0.001)$ than the other three populations, which did not differ significantly among them.

\section{Root growth and distribution}

Cañahua had a much smaller root system than the other populations throughout the experiment (Fig. 4a). At 63 DAS, TRL reached about $60 \mathrm{~m} \cdot$ plant $^{-1}$ in cañahua compared with an average of $620 \mathrm{~m} \cdot$ plant $^{-1}$ in the other three populations, which did not differ significantly among themselves (Fig. 4a). In all populations, the accelerated growth period for the whole root system was between 35 and 56 DAS. This corresponded to a slowing of the main root elongation from 42 DAS onwards (Fig. 1c) compensated for by the fast development of the lateral roots, which represented up to $98 \%$ of TRL and the total root biomass from 14 DAS onwards. SRL varied among populations and over time (Fig. $4 b$ ). From 21 DAS onwards, SRL in cañahua was significantly higher than the mean
Fig. 3. Relationship between net assimilation rate (NAR) and total plant mass (ln-transformed) in C. quinoa from low-resource habitat $\left(\triangle\right.$; dashed line; $\left.y=-0.68 x+10.25, r^{2}=0.54^{* *}\right)$ quinoa from highresource habitat $\left(\boldsymbol{\Lambda}\right.$; dotted line; $\left.\mathrm{y}=-0.68 x+10.58, r^{2}=0.56^{* *}\right)$, C. hircinum (๑; solid line; $\left.y=-0.63 x+11.35, r^{2}=0.46^{*}\right)$, and C. pallidicaule $\left(\bigcirc\right.$; dotted-dashed line; $\left.y=-0.75 x+8.05, r^{2}=0.54^{* *}\right)$ (*, significant at $P<0.1$; **, significant at $P<0.05 ; n=8$; each point is the mean of seven samples).

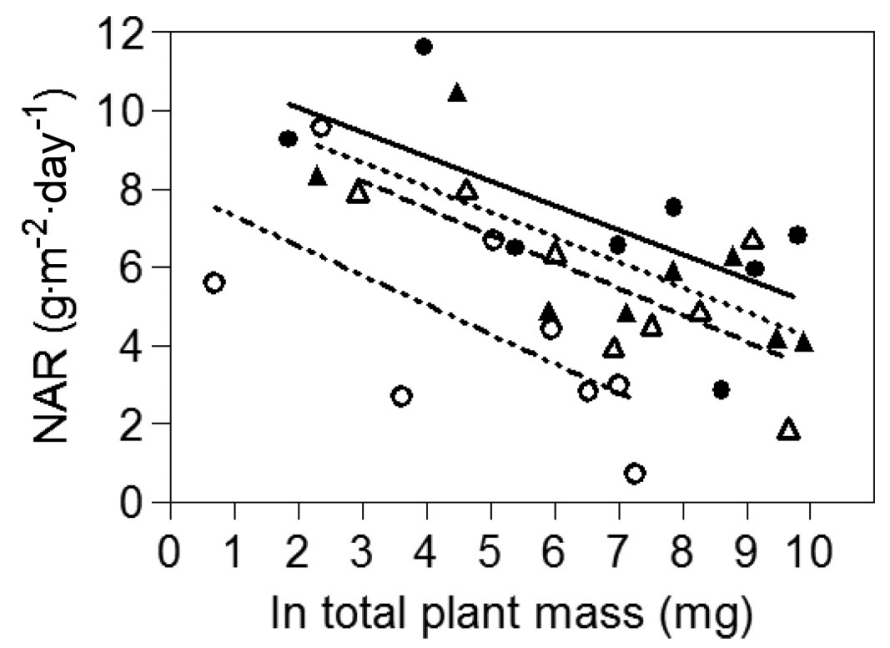

of the other three populations $\left(290.7 \pm 10.6 \mathrm{~m} \cdot \mathrm{g}^{-1}\right.$ compared with $\left.174.0 \pm 12.6 \mathrm{~m} \cdot \mathrm{g}^{-1}, \mathrm{P}<0.001\right)$.

Over the growing period, the average MRD remained limited to $0.5 \mathrm{~mm}$ in cañahua, which was nearly twice as low as in the other three populations (Fig. 4c). In these populations, the main root went through two phases of root thickening: first in the young 
Fig. 4. (a) Total root length (TRL), (b) specific root length (SRL), (c) main root diameter (MRD), and (d) lateral root diameter (LRD) (mm) in C. quinoa from low-resource habitat $(\triangle)$, C. quinoa from high-resource habitat $(\mathbf{\Delta})$, C. hircinum $(\bullet)$, and C. pallidicaule $(\bigcirc)(\mathrm{mean} \pm \mathrm{SE}, n=7$, vertical bars show SE unless eclipsed by the symbol).

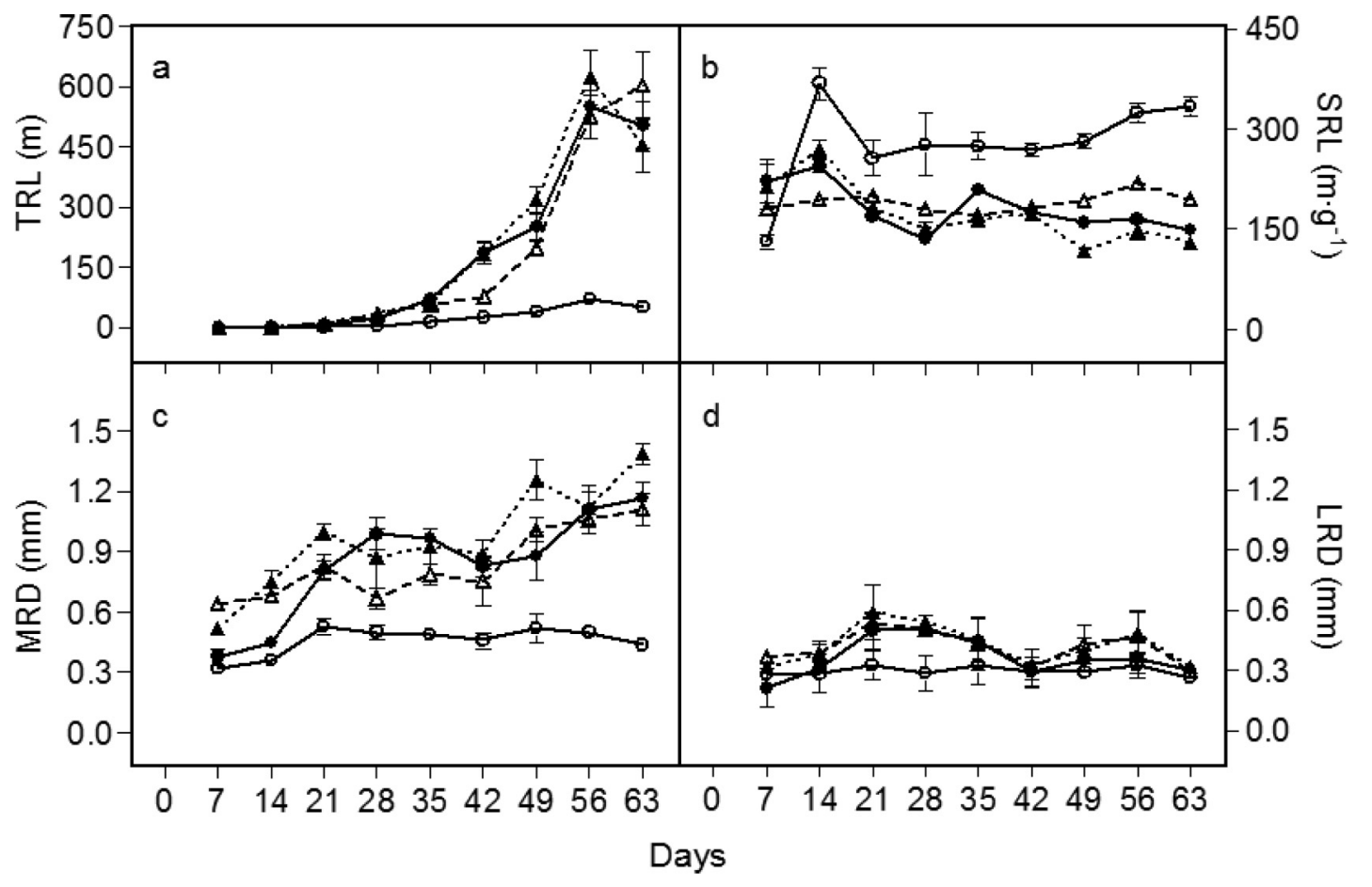

plants (until 21 DAS) and then in plants older than 42 days. The second phase of main root thickening coincided with the period of slow main root elongation (Fig. 1c) and fast lateral root elongation (Fig. 4a). Compared with the main root, lateral roots had a lower average diameter (ca. $0.3 \mathrm{~mm}$ ) without much variation either among populations or over time (Fig. $4 d$ ).

Most of the initial roots were finer than $0.3 \mathrm{~mm}$, representing up to $75 \%$ of TRL in C. hircinum and cañahua at 7 DAS (Fig. 5). Then, the fraction of thick roots (diameter $>0.3 \mathrm{~mm}$ ) increased rapidly up to 50\% until 21 DAS, except in cañahua where it remained nearly constant and limited at $25 \%$. This increase corresponded with the elongation and first thickening phase of the main root (Figs. $1 c$ and $4 c$ ) and was one week faster in the two quinoa populations compared with $C$. hircinum. The finest root fraction (diameter $<0.2 \mathrm{~mm}$ ) increased continuously, reflecting the progressive branching of the root system in all populations (Fig. 5).

\section{Discussion}

The present work postulates that Chenopodium populations show consistent phenotypic traits related to natural and human selection under contrasted soil resource availability. The specific hypothesis is that, to allow for survival in low-resource habitats, plants show morphological and growth traits that enhance soil resource capture. This comparative study is thus framed by two contrasts: one between wild and cultivated species, the other one between low- and high-resource habitats.

\section{Wild versus cultivated species}

Seed mass, plant morphology, and seedling growth clearly differentiated the four studied populations, with the two quinoa populations showing the largest seeds, the least branching stems, and the most vigorous seedlings in terms of biomass accumulation (Fig. 1, Supplementary Fig. S1). Considering the morphological and growth traits, the quinoa populations appeared closer to their wild progenitor, $C$. hircinum, than to their cultivated relative, cañahua (Figs. 1-4), as already noted by Bruno (2006). Interest- ingly, the branching stems characteristic of the wild C. hircinum developed within the same "pool" of total stem biomass as for the quinoa populations (ca. $40 \%$ of the total plant biomass at 63 DAS in both species; Supplementary Fig. S1). It thus appears that domestication of quinoa did not change the overall proportions of leaf, stem, and root mass already present in the wild progenitor but resulted in a significantly reduced proportion of secondary stems (Supplementary Fig. S1). In cañahua, the total SMF was similar to that in the other two species, but stem branching remained largely dominant. This branched growth habit in cañahua is still present, although marginally so, in the quinoa populations and should give these cultivated species a higher potential of adaptability against microsite, weather, and biotic variations (Janssens et al. 1990). The four populations shared a large number of morphology and growth traits, starting with the dynamics in biomass allocation. From germination to floral bud bursting, all populations followed a three-phase sequence of growth processes: (i) progressive onset of the autonomous carbon fixation by the leaves in the first 14 DAS, (ii) fast exploration of deep soil layers by the main root until 28 to 35 DAS, and (iii) proliferation of lateral roots sustaining an accelerated shoot growth by the end of the vegetative period (Supplementary Fig. S1). This sequential pattern of biomass allocation observed under nonlimiting conditions in wild, as well as cultivated, populations conforms the general ontogenetic trend described for vegetative eudicots (Poorter et al. 2011). It also corresponds with the fast early growth of quinoa seedlings observed by Ruffino et al. (2010). This pattern is in agreement with the findings of Janssens et al. (1990) assuming that cultivated species in low-input agriculture retain a high proportion of ancestral characteristics. The initial priority to leaf growth in terms of biomass did not imply a reduced role of the root system: high RA/LA values at the earliest growth stage show that, in emerging seedlings, the exchange area was equal or larger in roots than in leaves, suggesting a balance between soil foraging and light capture during the early stages of plant life (Supplementary Fig. S2b). 
Fig. 5. Time variation in the total root length distribution among five classes of root diameter in C. quinoa from low-resource habitat (QB), C. quinoa from high-resource habitat $(\mathrm{QC})$, C. hircinum (HI), and C. pallidicaule (PA).

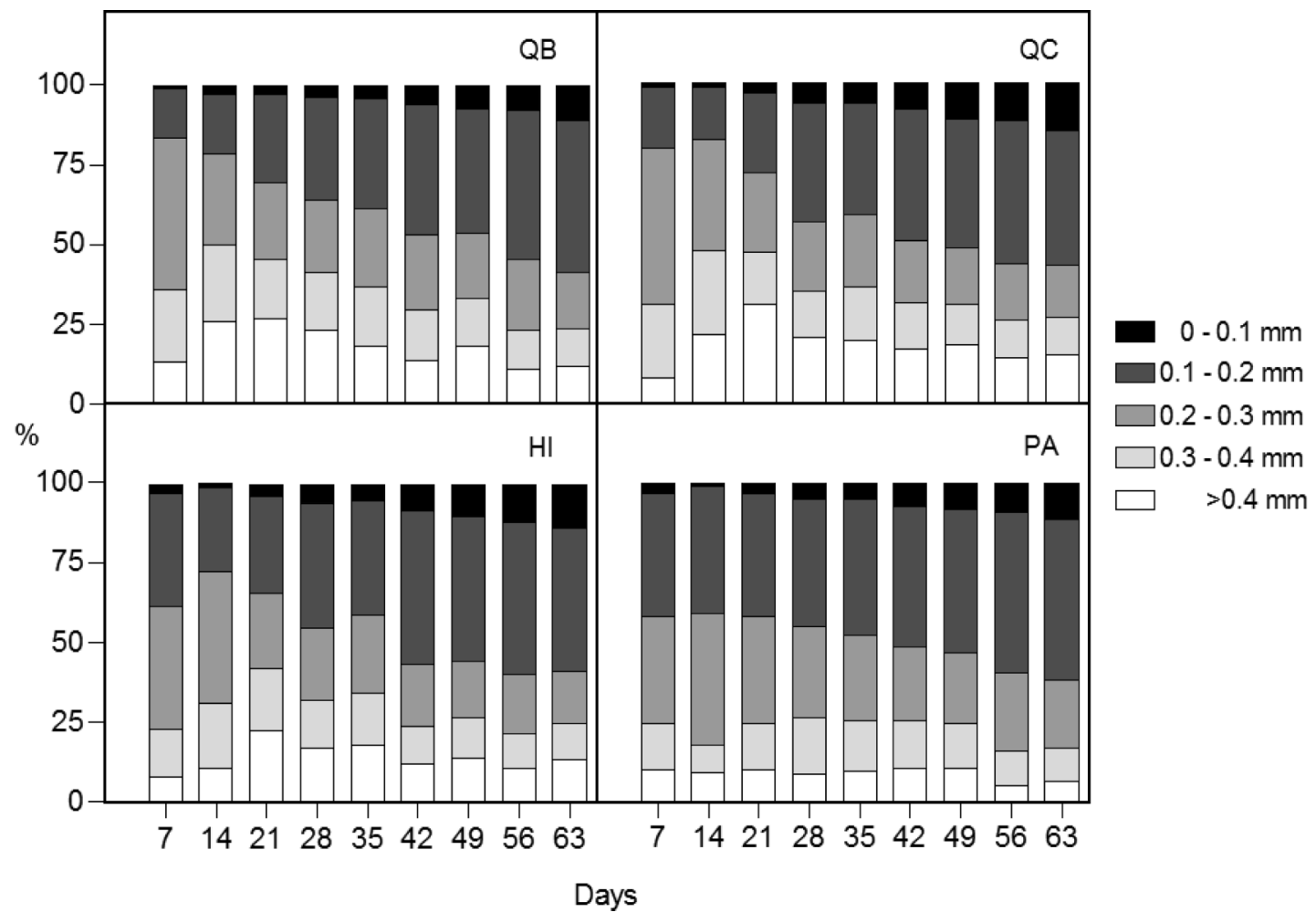

Other growth parameters such as SLA, RA/LA, LAR, and maximum root or shoot RGR showed similar values in the four populations (Fig. 2; Supplementary Figs. S2b, S3a, and S3b). The decrease in SLA over time agrees with the trend reported by Jensen et al. (2000) for field-grown quinoa, although the values observed in the present study were nearly twice as high. Lower light irradiance and higher air temperature in glasshouse compared with field experiments could be the cause of this difference in SLA (Poorter et al. 2009). The high correlation between LAR and SLA over a range of plant size suggests that the influence of SLA on variations in LAR observed across species (Poorter et al. 2011) also holds when considering the ontogenetic variations in LAR related to changes in plant size and leaf morphology during the vegetative growth phase.

In view of the many similarities in the morphology and growth patterns in the studied species, the major contrast between them appeared related to ploidy, the tetraploid $C$. hircinum and quinoa being much more productive than the diploid cañahua in terms of TPM, NAR, and TRL (Figs. 1a, 3, 4a). Both tetraploid species had root axes that were significantly thicker than in cañahua, which results in lower SRL values (Figs. $4 b, 4 c, 4 d$ ). These traits contribute to the penetration capacity of the roots and, thus, to the competitive ability of the plants to explore the soil profile (Materechera et al. 1992). Plants with roots of low SRL tend to have lower root respiration and lower root turnover rates than those with roots of high SRL (Roumet et al. 2006). The two tetraploid species showed generally the highest values of $R / S$ (Supplementary Figs. S1, S2a). This higher investment in the root system together with a lower cost of root maintenance might explain the higher overall productivity and slower RGR decrease in C. hircinum and quinoa compared with cañahua.

Depending on the species, the correlation between RGR and seed mass can be positive, negative, or null (Grime and Hunt 1975; Bell 2005; Villar et al. 1998). In the present study, the small-seeded cañahua and the medium-seeded $C$. hircinum showed maximum values of root and shoot RGR similar to those in the large-seeded quinoa, thus without correlation with seed mass. Other cases of small seed mass associated with high RGR have been described in wild and cultivated relatives (Grime and Hunt 1975; Chapin et al. 1989). Evans (1993) states that crop domestication did not result in any consistent difference in RGR among wild and cultivated species. The present study showed that, despite similar maximum values of root or shoot RGR, the four populations differed in the changes of these growth parameters in relation to plant size (Fig. 2). In cañahua, the lower threshold values for the progressive decrease in root or shoot RGR were associated with the lower early vigour and general lower productivity of this species, themselves related to its lower seed mass. Ploidy level could play a role in the association between seed mass and vigour in early plant growth, although a direct relationship remains difficult to establish (Evans 1993). Among the studied species of larger seed mass, prolonged high values of root RGR at medium plant size (ln TPM between 5 and 6.5 in Fig. 2) were characteristic of the two quinoa populations and were associated with a vigorous root growth for a longer time period than in the wild $C$. hircinum. This could be related to the higher main root diameter and higher proportion of coarse root $(>0.3 \mathrm{~mm}$ ) in the quinoa populations until 21 DAS (Figs. $4 c, 5)$, both traits indicating a root system with stronger morphology in the young quinoa plants compared with their wild ancestor.

The present work showing interspecific differences in root growth rate and root morphology under a common environment suggests that these traits are genetically controlled in the studied species and that root systems in quinoa may have been positively influenced by human selection. Similar conclusions have been drawn comparing old and modern wheat cultivars grown under drought-prone environments (Siddique et al. 1990; Palta et al. 2011). These studies on wheat, as well as the present experiment on Andean chenopods, found that human improvement of seed crops has indirectly favoured the development of a strong root system during the early stages of the vegetative period, notably 
through the rapid growth of a coarse main root and many secondary root branches. Such root morphology during early growth stages is an advantage for the fast colonization of deep soil layers, enhancing the acquisition of ephemeral soil resources (Wasson et al. 2012; Lamb et al. 2012) and thus contributing to better seedling competitivity and early vigour in domesticated species compared with wild ones (Janssens et al. 1990; Wolfe et al. 2008).

\section{Low- versus high-resource habitats}

In the present study, the contrast in plant traits between populations from low- and high-resource habitats is mainly illustrated by comparing quinoa from the dry highlands with quinoa from the humid lowlands, while cañihua brings insights on plant traits adapted to extremely high and cold habitats with shallow soils. This comparison assumes that (i) differences in environmental conditions have been consistent over time and plant dispersal was limited enough to allow genetic differentiation among populations and (ii) genetic differentiation is expressed even under uniform and nonlimiting growth conditions. Although the first assumption seems reasonably satisfied when comparing the arid and cold Bolivian highlands with the rainy and temperate Chilean lowlands ca. $2100 \mathrm{~km}$ apart, the fulfillment of the second assumption remains more uncertain. In fact, under nonlimiting conditions, the two quinoa populations showed only marginal differences in their morphological and growth patterns despite contrasted habitats of origin. The most notable difference between them lies in the seed mass, which is significantly higher in the quinoa from the low-resource habitat. Baker (1972) states that large-seeded species tend to be found in environments where seedlings are exposed to drought, whereas Villar et al. (1998) reported a lack of correlation. Phenotypic variation in quinoa seed mass has been documented at the continental scale (Bhargava et al. 2007), but the lack of precise location of the origin of the studied lines precludes inferring any biological adaptation. Within the Bolivian germplasm, Rojas (2003) finds larger seeds in quinoa from the arid southern altiplano compared with less dry habitats. Because seed mass is directly related to energy availability in the endosperm and early exposition of the cotyledons after emergence (Moles and Leishman 2008), larger seeds should confer better plant vigour and competitive ability in seedlings of quinoa from low-resource habitats. The high MRL in this population, jointly with the high fraction of coarse roots, might reflect a priority to fast and continued colonization of the soil at depth, an adaptive rooting pattern for capture of soil water and nutrients in low-resource habitats. Similar differences in root depth and distribution have been observed in wild legume species from climatically contrasted locations compared under uniform conditions (Bell 2005).

From an ecological perspective, the low productivity displayed by cañahua, together with its branched growth habit, low NAR, and high SRL, could be part of a syndrome of plant growth adapted to cold, high-altitude habitats with shallow soils (Poorter et al. 2011; Gade 1970). In fact, small, branched plants are less exposed to the night frosts frequent in the Andean highlands (Pouteau et al. 2011; Winkel et al. 2009). The high SRL value, indicative of a strategy of rapid resource acquisition, could partly compensate for the limited soil foraging capacity in this species.

\section{Conclusion}

This study shows that wild and cultivated populations of Chenopodium from contrasted habitats display both differences and similarities in plant morphology and growth patterns. Interspecific variation under common nonlimiting conditions suggests that these morphological differences are genetically controlled. Seed mass and ploidy level were the primary factors controlling early growth and allocation patterns among the studied species. Biomass production in quinoa seedlings was not higher than in their wild relative, but shoot branching architecture was modified. The morphology and growth dynamics of the root system was also changed in the cultivated populations, improving their capacity to explore soil at greater depth during early growth stages. Although this study in a common environment under nonlimiting conditions allowed inference of a genetic basis for the phenotypic variations observed among species, the adaptive value of these variations should still be assessed along agroenvironmental gradients.

\section{Acknowledgements}

The authors are grateful to Felix Mamani Reynoso and Alejandro Bonifacio (Universidad Mayor de San Andrés (UMSA), La Paz, Bolivia) for kindly providing the seeds of cañahua and $C$. hircinum and to the staff of the experimental field at Centre d'Ecologie Fonctionnelle et Evolutive (Montpellier, France) for technical assistance. The root analyses were performed at the Plateforme d'Analyses Chimiques en Écologie, technical facilities of the LabEx Centre Méditerranéen de l'Environnement et de la Biodiversité. This research was funded by a PhD grant of the CONICYT (Comisión Nacional de Investigación Científica y Tecnológica, Chile) and by the ANR (Agence Nationale de la Recherche, France) under the programme ANR-06-PADD-011-EQUECO.

\section{References}

Alvear, M., Rosas, A., Rouanet, J.L., and Borie, F. 2005. Effects of three soil tillage systems on some biological activities in an Ultisol from southern Chile. Soil Tillage Res. 82: 195-202. doi:10.1016/j.still.2004.06.002.

Anabalón Rodríguez, L., and Thomet Isla, M. 2009. Comparative analysis of genetic and morphologic diversity among quinoa accessions (Chenopodium quinoa Willd.) of the South of Chile and highland accessions. J. Plant Breed. Crop Sci. 1: 210-216.

Baker, H.G. 1972. Seed weight in relation to environmental conditions in California. Ecology, 53: 997-1010. doi:10.2307/1935413.

Bell, L.W. 2005. Relative growth rate, resource allocation and root morphology in the perennial legumes, Medicago sativa, Dorycnium rectum and D. hirsutum grown under controlled conditions. Plant Soil, 270:199-211. doi:10.1007/s11104004-1495-6.

Bertero, H.D., de la Vega, A.J., Correa, G., Jacobsen, S.E., and Mujica, A. 2004. Genotype and genotype-by-environment interaction effects for grain yield and grain size of quinoa (Chenopodium quinoa Willd.) as revealed by pattern analysis of international multi-environment trials. Field Crops Res. 89: 299318. doi:10.1016/j.fcr.2004.02.006.

Bhargava, A., Shukla, S., and Ohri, D. 2007. Genetic variability and interrelationship among various morphological and quality traits in quinoa (Chenopodium quinoa Willd.). Field Crops Res. 101: 104-116. doi:10.1016/j.fcr.2006.10.001.

Bonifacio, A. 2003. Chenopodium sp.: genetic resources, ethnobotany, and geographic distribution. Food Rev. Int. 19: 1-7. doi:10.1081/FRI-120018863.

Bruno, M.C. 2006. A morphological approach to documenting the domestication of Chenopodium in the Andes. In Documenting domestication: new archaeological and genetic paradigms. Edited by M.A. Zeder, E. Emshwiller, B.D. Smith, and D.G. Bradley. University of California Press, Berkeley, California. pp. 32-45.

Causton, D.R. 1991. Plant growth analysis: the variability of relative growth rate within a sample. Ann. Bot. 67: 137-144.

Chapin, F.S., Groves, R.H., and Evans, L.T. 1989. Physiological determinants of growth rate in response to phosphorus supply in wild and cultivated Hordeum species. Oecologia, 79: 96-105. doi:10.1007/BF00378245.

Coleman, J.S., McConnaughay, K.D.M., and Ackerly, D.D. 1994. Interpreting phenotypic variation in plants. Trends Ecol. Evol. 9: 187-191. doi:10.1016/01695347(94)90087-6. PMID:21236817.

Costa Tártara, S.M., Manifesto, M.M., Bramardi, S.J., and Bertero, H.D. 2012. Genetic structure in cultivated quinoa (Chenopodium quinoa Willd.), a reflection of landscape structure in Northwest Argentina. Conserv. Genet. 13: 1027-1038. doi:10.1007/s10592-012-0350-1.

Del Castillo, C., Winkel, T., Mahy, G., and Bizoux, J.-P. 2007. Genetic structure of quinoa (Chenopodium quinoa Willd.) from the Bolivian altiplano as revealed by RAPD markers. Genet. Res. Crop Evol. 54: 897-905. doi:10.1007/s10722-0069151-z.

Evans, L.T. 1993. Crop evolution, adaptation and yield. Cambridge University Press, Cambridge, UK.

Gade, D.W. 1970. Ethnobotany of cañihua (Chenopodium pallidicaule), rustic seed crop of Altiplano. Econ. Bot. 24: 55-61. doi:10.1007/BF02860637.

Garnier, E. 1991. Resource capture, biomass allocation and growth in herbaceous plants. Trends Ecol. Evol. 6: 126-131. doi:10.1016/0169-5347(91)90091-B. PMID: 21232441.

Grime, J.P., and Hunt, R. 1975. Relative growth-rate: its range and adaptive significance in a local flora. J. Ecol. 63: 393-422. doi:10.2307/2258728.

Henry, A., Gowda, V.R.P., Torres, R.O., McNally, K.L., and Serraj, R. 2011. Varia tion in root system architecture and drought response in rice (Oryza sativa): 


\section{Pagination not final (cite DOI) / Pagination provisoire (citer le DOI)}

phenotyping of the OryzaSNP panel in rainfed lowland fields. Field Crops Res. 120: 205-214. doi:10.1016/j.fer.2010.10.003.

Hoffmann, W.A., and Poorter, H. 2002. Avoiding bias in calculations of relative growth rate. Ann. Bot. 90: 37-42. doi:10.1093/aob/mcf140. PMID:12125771.

Janssens, M.J.J., Neumann, I.F., and Froidevaux, L. 1990. Low-input ideotypes. In Agroecology: researching the ecological basis for sustainable agriculture. Edited by S.R. Gliessman. Springer, Berlin. pp. 130-145.

Jensen, C.R., Jacobsen, S.-E., Andersen, M.N., Núñez, N., Andersen, S.D., Rasmussen, L., and Mogensen, V.O. 2000. Leaf gas exchange and water relation characteristics of field quinoa (Chenopodium quinoa Willd.) during soil drying. Eur. J. Agron. 13: 11-25. doi:10.1016/S1161-0301(00)00055-1.

Lamb, E.G., Stewart, A.C., and Cahill, J.F. 2012. Root system size determines plant performance following short-term soil nutrient pulses. Plant Ecol. 213: 18031812. doi:10.1007/s11258-012-0135-0.

Lebonvallet, S. 2008. Implantation du quinoa et simulation de sa culture sur l'altiplano bolivien. Ph.D. thesis, AgroParisTech, Paris, France.

Materechera, S.A., Alston, A.M., Kirby, J.M., and Dexter, A.R. 1992. Influence of root diameter on the penetration of seminal roots into a compacted subsoil. Plant Soil, 144: 297-303. doi:10.1007/BF00012888.

Moles, A.T., and Leishman, M. 2008. The seedling as part of a plant's life history strategy. In Seedling ecology and evolution. Edited by M.A. Leck, V.T. Parker, and R.L. Simpson. Cambridge University Press, Cambridge, UK. pp. 217-237.

Mujica, A., Izquierdo, J.I., and Marathée, J.P. 2001. Origen y descripción de la quinua. In Quinua (Chenopodium quinoa Willd.): ancestral cultivo andino, alimento del presente y futuro. Edited by A. Mujica, S.E. Jacobsen, J.I. Izquierdo, and J.P. Marathée. CD-Rom: Cultivos Andinos. Version 1.0. FAO, Santiago, Chile.

Palta, J.A., Chen, X., Milroy, S.P., Rebetzke, G.J., Dreccer, M.F., and Watt, M. 2011. Large root systems: are they useful in adapting wheat to dry environments? Funct. Plant Biol. 38: 347-354. doi:10.1071/FP11031.

Pearsall, D.M. 2008. Plant domestication and the shift to agriculture in the Andes. In The handbook of South American archaeology. Edited by H. Silverman and W.H. Isbell. Springer, New York. pp. 105-120.

Poorter, H., Niinemets, Ü., Poorter, L., Wright, I.J., and Villar, R. 2009. Causes and consequences of variation in leaf mass per area (LMA): a meta-analysis. New Phytol. 182: 565-588. doi:10.1111/j.1469-8137.2009.02830.x. PMID:19434804.

Poorter, H., Niklas, K.J., Reich, P.B., Oleksyn, J., Poot, P., and Mommer, L. 2011. Biomass allocation to leaves, stems and roots: meta-analyses of interspecific variation and environmental control. New Phytol. 193: 30-50. doi:10.1111/j. 1469-8137.2011.03952.x. PMID:22085245.

Pouteau, R., Rambal, S., Ratte, J.P., Gogé, F., Joffre, R., and Winkel, T. 2011. Downscaling MODIS-derived maps using GIS and boosted regression trees: the case of frost occurrence over the arid Andean highlands of Bolivia. Remote Sens. Environ. 115: 117-129. doi:10.1016/j.rse.2010.08.011.

Reich, P.B., Tjoelker, M.G., Walters, M.B., Vanderklein, D.W., and Buschena, C. 1998. Close association of RGR, leaf and root morphology, seed mass and shade tolerance in seedlings of nine boreal tree species grown in high and low light. Funct. Ecol. 12: 327-338. doi:10.1046/j.1365-2435.1998.00208.x.

Reyes, F., Lillo, A., Ojeda, N., Reyes, M., and Alvear, M. 2011. Efecto de la exposición y la toposecuencia sobre actividades biológicas del suelo en bosque relicto del centro-sur de Chile. 92002011000300007.

Rojas, W. 2003. Multivariate analysis of genetic diversity of Bolivian quinoa germplasm. Food Rev. Int. 19: 9-23. doi:10.1081/FRI-120018864.

Ross-Ibarra, J., Morrell, P.L., and Gaut, B.S. 2007. Plant domestication, a unique opportunity to identify the genetic basis of adaptation. Proc. Natl. Acad. Sci. Am. 104(Suppl. 1): 8641-8648.

Roumet, C., Urcelay, C., and Díaz, S. 2006. Suites of root traits differ between annual and perennial species growing in the field. New Phytol. 170: 357-368. doi:10.1111/j.1469-8137.2006.01667.x. PMID:16608460.

Ruffino, A., Rosa, M., Hilal, M., González, J., and Prado, F. 2010. The role of cotyledon metabolism in the establishment of quinoa (Chenopodium quinoa) seedlings growing under salinity. Plant Soil, 326: 213-224. doi:10.1007/s11104009-9999-8.

Siddique, K.H.M., Belford, R.K., and Tennant, D. 1990. Root:shoot ratios of old and modern, tall and semi-dwarf wheats in a Mediterranean environment. Plant Soil, 121: 89-98. doi:10.1007/BF00013101.

Vernon, A.J., and Allison, J.C.S. 1963. A method of calculating net assimilation rate. Nature, 200: 814-814. doi:10.1038/200814a0.

Villar, R., Veneklaas, E.J., Jordano, P., and Lambers, H. 1998. Relative growth rate and biomass allocation in 20 Aegilops (Poaceae) species. New Phytol. 140: 425-437. doi:10.1046/j.1469-8137.1998.00286.x.

Wasson, A.P., Richards, R.A., Chatrath, R., Misra, S.C., Sai Prasad, S.V., Rebetzke, G.J., Kirkegaard, J.A., Christopher, J., and Watt, M. 2012. Traits and selection strategies to improve root systems and water uptake in waterlimited wheat crops. J. Exp. Bot. 63: 3485-3498. doi:10.1093/jxb/ers111. PMID: 22553286.

Wilson, H.D. 1990. Quinua and relatives (Chenopodium sect. Chenopodium subsect. Cellulata). Econ. Bot. 44: 92-110. doi:10.1007/BF02860478.

Winkel, T., Lhomme, J.P., Laura, J.P.N., Alcón, C.M., Del Castillo, C., and Rocheteau, A. 2009. Assessing the protective effect of vertically heterogeneous canopies against radiative frost: the case of quinoa on the Andean Altiplano. Agric. For. Meteorol. 149: 1759-1768. doi:10.1016/j.agrformet.2009. 06.005.

Wolfe, M.S., Baresel, J.P., Desclaux, D., Goldringer, I., Hoad, S., Kovacs, G., Löschenberger, F., Miedaner, T., Østergård, H., and Lammerts van Bueren, E.T. 2008. Developments in breeding cereals for organic agriculture. Euphytica, 163: 323-346. doi:10.1007/s10681-008-9690-9.

Yu, G.R., Zhuang, J., Nakayama, K., and Jin, Y. 2007. Root water uptake and profile soil water as affected by vertical root distribution. Plant Ecol. 189: 15-30. doi:10.1007/s11258-006-9163-y. 